\title{
CLAPO syndrome
}

INSERM

\section{Source}

INSERM. (1999). Orphanet: an online rare disease and orphan drug data base. CLAPO

syndrome. ORPHA:168984

CLAPO syndrome is a newly described syndrome consisting of capillary malformation of the lower lip (C), lymphatic malformation of the face and neck (L), asymmetry of face and limbs (A) and partial or generalized overg rowth (O). 